\title{
EMPLOYEE REVIEWS ON COMPANY INDEPENDENT SITES AND ITS IMPACT ON ORGANIZATIONAL ATTRACTIVENESS: ROLE OF INFORMATION REALISM, PERSON - ENVIRONMENT FIT AND SOURCE CREDIBILITY FRAMEWORK
}

\author{
Tavleen KAUR ${ }^{1}$, Ritesh Kumar DUBEY ${ }^{2}$
}

\author{
IBS Hyderabad, Survey No. 156/157, Dontanapally Village, Shankerpalli, Mandal, Ranga Reddy District, \\ Hyderabad-501504, India \\ E-mails: ${ }^{1}$ tavleenkaur@ibsindia.org (correspondingauthor); ${ }^{2}$ riteshdubey@ibsindia.org
}

Received 10 December 2013; accepted 27 February 2014

\begin{abstract}
Extant literature on recruitment has focused on the traditional sources of recruitment like company brochures, career fairs, and impact of such sources on intent to join the organization, productivity and turnover intention. The influence of recruitment related information on pre hire outcomes is still scarce and inconclusive. With the advent of technology and access to Internet, company websites have become an important source of recruitment. Apart from company websites, job seekers are now using company independent websites, forums or online communities to gather a more truthful picture and information about the job and organizational attributes. Social media too has become increasingly important medium where the current employees' share how it is to work with the organization However research on web based recruitment is limited to company websites. Despite the widespread growth and practical use of these new and innovative media very little is known about how these independent sites influence recruitment pre hire outcomes. In this direction the proposed study presents a conceptual framework about how job seekers perceive company independent websites as a tool for providing recruitment communication and their impact on organizational attractiveness using Information Realism, Person-Environment fit framework, Source Credibility framework.
\end{abstract}

Keywords: recruitment, company websites, Person-Organization, Person-Job fit, credibility, realism.

JEL Classification: M12, M51, M59.

\section{Introduction}

Recruitment consists of those organizational activities and practices whose primary goal is to identify and attract potential employees and persuade them toward becoming an organizational member (Barber 1998; Breaugh, Starke 2000). Recruitment remains an important function for at least two reasons. First, there will always be certain hard to fill vacancies for which the organizations must compete fiercely to attract potential applicants, even in an otherwise loose labor market. Second, the most talented job seekers continue to have enough options to critically investigate and compare potential employers. Therefore organizations that wish to attract these highly desired potential applicants have no choice but to participate in the "war of talent" (Cappelli 2001).
Barber (1998) has delineated three phases of recruitment. The first phase includes identifying potential applicants and persuading them to apply in the organization. This is about targeting a particular segment of the job market. There is minimal personal contact during the first phase and both the parties have limited information about each other. The second phase includes the applicant pool - those who choose to apply in the organization and this phase includes more detailed information. During this phase the organization tries to persuade the candidates to stay interested in the organization till they make their final decision. In the last phase the candidates decide whether to accept or reject the job offers, which includes motivating the selectees to accept the job offers and become new employees. Recruitment activities are most influential and useful during the initial phases.

Copyright (C) 2014 The Authors. Published by VGTU Press.

This is an open-access article distributed under the terms of the Creative Commons Attribution-NonCommercial 4.0 (CC BY-NC 4.0) license, which permits unrestricted use, distribution, and reproduction in any medium, provided the original author and source are credited. The material cannot be used for commercial purposes.

To link to this article: http://dx.doi.org/10.3846/btp.2014.404 
In context of external recruitment, Breaugh (2008) stated that the manner in which the employer recruits is important for two reasons. Firstly if an employer does a poor job of recruiting, it may not bring vacancies to the attention of the type of applicants it wants to recruit. Secondly even if a job vacancy is brought to the attention of targeted individuals, poor treatment during the process e.g. poorly run website may result in job applicants withdrawing from the process. The use of internet or web for providing recruiting information is changing the nature of communication. Websites provide the opportunity to communicate practically unlimited amount of information to unlimited audience which is geographically dispersed at a relatively low cost.

Organizations use different media for communicating information particularly in recruitment context like career fairs, company websites, company brochures, campus placements etc. Internet has become an important medium for both recruiters and the recruits to gather information about each other. For organizations internet is a less costly and more efficient way to provide job and organizational information to the job seekers. Earlier job seekers used to consult newspapers and friends for gathering information about potential employers; however with the increased use of Internet, job seekers now get information from websites, chat rooms and social media sites. On one hand there is lot of information that is supplied by the company via company websites, recruitment advertising, etc. On the other hand there is a lot of information about organizations "going around" on internet (Dellarocas 2003; Van Hoye, Lievens 2007). Job seekers can quickly search for such independent information about the organization from employee's blogs, chat rooms and company independent websites. So far research has focused on company dependent websites where the information is completely controlled by the organization whereas company independent sources have largely been ignored (Cable, Turban 2001; Van Hoye, Lievens 2007; Walker et al. 2009).

The source of providing recruitment information and the medium used to communicate such information influences the attractiveness towards the organization. One of the ways of providing recruitment related information is through employee testimonials. Research on the usefulness of employee testimonials has so far focused on corporate websites, which are under the control of organizations (Van Hoye, Lievens 2007; Walker et al. 2009). Apart from corporate websites, social media tools like online communities, forums are becoming popular. The combination of providing recruitment information in form of employee testimonials on company independent sites holds the potential to attract prospective employees and communicate a positive employment image.

The present study suggests certain propositions that would help in determining which of the sources among company dependent and company independent would provide more realistic information regarding job and organizational attributes, which source would be perceived more credible and which of the two sources would provide better-fit perceptions about person-job and person-organization. The study also provides a conceptual framework determining how realistic information leads to organizational attractiveness.

\section{Literature review: web based recruitment}

Walker et al. (2009) claim that the use of media to communicate organizational information increases the likelihood that job seekers develop preferred image beliefs. When job seekers start their job search process, corporate website is typically one of the first tools to gather information and evaluate prospective employers. The way the organizations communicate through their websites is a crucial determinant of getting qualified applicants (Williamson et al. 2003; Cappelli 2001).

Recruitment websites can develop perceptions of organizational attractiveness through web site usability. In recruitment context this would mean that relationship between website and organizational attractiveness could be explained by usability perceptions of individuals. Web site usability influences organizational attractiveness through content usefulness which refers to perceived usefulness of the information posted on the web site and ease of use (Williamson et al. 2003).

Most of the research on web based recruitment has focused on website usability, features and aesthetics of the website (Cober et al. 2004; Dineen et al. 2002; Williamson et al. 2003). Aesthetic features include attractive colors, pleasing texts, and pictures. Apart from features, aesthetics and website usability, the amount of information provided in the recruitment websites also influence organizational attractiveness. The more job and organizational related information is provided on such websites, the more the job applicants are attracted towards the organization (Williamson et al. 2003; Allen et al. 2004).

Informational characteristics like amount of information, uniqueness, and specificity of the information provided also affect attraction towards the organization (Barber 1998). Allen, Biggane, Pitts, Ottondo and Scotter (2013) evaluated these informational characteristics in the context of corporate websites. The authors opine that one of the primary advantages of recruitment websites is the ability to present more amount and different types of information. Receivers pay more attention to specific, unique information and unexpected information (Allen et al. 2013).

The first point of contact of prospective employees with the organizations is usually the corporate website (Allen et al. 2004; Cable, Yu 2006). However only having 
a corporate website of good quality is not sufficient. The advent of information technology and especially web 2.0 has introduced many engaging tools and new ways of interacting such as blogs, micro blogs and other social media tools (Briones et al. 2011). There are two major internet channels for organizations to communicate with the external audiences: Corporate websites and social networking websites (Bondarouk et al. 2012). Despite their presumed advantages in practice, empirical support considering social media effects on pre hires recruitment outcomes are scarce.

Research indicates that in Europe $84 \%$ of all activities on the internet are related to social networking sites (Bondarouk et al. 2012). Cappelli (2001) found that $90 \%$ of American companies are using social networking websites to communicate information to outsiders. Attracting new generation of employees is becoming increasingly important for businesses. The new generation of young professionals is often referred to as Generation Y. Some of the qualities ascribed to them are feeling more comfortable in informal settings than formal settings, digitally skilled, socially active both online and offline and connecting their digital and physical world seamlessly (Briones et al. 2011).

The emergence of social media tools has increased capabilities for interactive communication and information sharing online. The participatory nature and instant feedback of social media adds to degree of interactivity. Organizations have started incorporating social media elements into their marketing and promoting strategies and fostering two-way communications between consumers and brands (Park et al. 2009).

According to Kaplan and Haenlein (2010) "social media is a group of online applications that are based on ideology and technology of web 2.0 and enable the creation and exchange of user generated content". The term social media doesn't have clearly defined borders and the term web 2.0 and social media have been used interchangeably. According to (Girard et al. 2013) there are two main types of social media namely social networking sites and social media sites. The main objective of social networking is connecting with other people and therefore people create a personal profile like Facebook, LinkedIn. The key purpose of social media sites is sharing of media content like YouTube, Forums etc.

Recruitment is one of the main HR activity affected by the rise of social media. Vicknair, Elkersh, Yancey, Budden (2010) are of the opinion that using social networking websites for screening and recruiting purposes has become a trend. According to Clark and Roberts (2010) employers these days use social networking websites especially Facebook for conducting background checks on prospective candidates. Facebook, My space, and numerous blogs are being utilized by growing number of recruiters, potential employers and current employers. The use of these sites now extends beyond simply befriending people, to extensive personal networks that seek information about employers, employees and job opportunities (Waring, Buchanan 2010). On Company independent sites, current employees share their experiences about how it is to work with the organization and it falls under the discussion tools category of social media tools. Despite the use and importance of social media tools other than corporate websites, there is lack of empirical research on them (Van Hoye, Lievens 2007).

\section{Company dependent v/s company independent sources}

A key distinction between recruitment sources can be made as Company dependent and company independent (Cable, Turban 2001; Van Hoye, Lievens 2007). Company dependent sources such as advertising are part of the company recruitment activities and can be directly controlled to communicate a positive message to potential applicants. Conversely company independent sources such as word of mouth can be influenced only indirectly through other recruitment activities and can contain positive as well as negative information. Compared to company dependent information sources company independent sources are more likely to be perceived as credible, as they do not have the explicit purpose of selling the organization (Van Hoye, Lievens 2007).

Job applicants receive information from sources like recruitment advertising, recruiters, publicity and word of mouth. Recruitment advertising represents the most common and typical example of a company dependent recruitment source. Examples include recruitment brochures and company web pages (Van Hoye, Lievens 2007). A typical example of company independent recruitment source is word of mouth and can be defined as "interpersonal communication, independent of organization's recruitment activities about an organization as an employer or about specific jobs" (Van Hoye, Lievens 2007). Examples include conversations with friends and advice from independent experts. Usually word of mouth is typically associated with face-to-face interaction that can be provided through other medium like telephone or Internet. The importance of web-based word of mouth is evident from the emergence and increased use of chat-rooms, electronic boards and independent websites presenting interpersonal company information (Dellarocas 2003).

\section{Source credibility}

The information a job applicant receives about a job and an organization can come from variety of sources including interviewers, other company employees or friends, acquaintances not directly associated with the organization. The source from which the job seeker receives information influences the reactions towards that information (Fisher 
et al. 1979). Sources of recruitment differ in terms of perceived credibility, which implies that recruitment sources differ in the degree to which the job applicants perceive them to be credible (Cable, Turban 2001). Source credibility has two dimensions namely expertise and trustworthiness. "Expertise refers to the extent to which a speaker is perceived to be capable of making correct assertions, and trustworthiness refers to the degree to which an audience perceives the assertions made by a communicator to be the ones that the speaker considers valid" (Pornpitakpan 2004).

Credibility is critically important in persuasive communication, attitude change and attaining behavioral compliance (Perloff 1993). Breaugh and Starke (2000) suggested that credibility might be one important intervening variable between recruitment activities and outcomes.

In the recruitment context when organizations are trying to sell organizational characteristics to the potential applicants, more credible sources are likely to generate positive responses (Allen et al. 2013). With respect to expertise job incumbents are perceived to have more experience about the job, as they are closest to work than corporate recruiters. With regard to trustworthiness, receiving information that is different than expected from the message source is perceived to be more credible. Full time recruiters are seen as less trustworthy as they present an overly positive picture of job and organizational attributes. Communicators who convey information that detracts from their position are rated as more trustworthy than communicators who cite information that conforms to their position (Breaugh 2000; Fisher et al. 1979).

Fisher et al. (1979) stated that recruiter credibility helps in explaining the differential effects on recruitment outcomes. The authors found that in comparison of four sources (interviewer, job incumbent, friend and a professor) the most credible source is job incumbent. The sources were trusted more when they gave unfavorable information rather than overly positive information. The basis for this assertion is that corporate recruiters are viewed as lacking expertise, concerning what the job entails, and are perceived as having a vested interest of selling the organization and filling the vacancy. In an employment setting, the interviewer and recruiter are perceived to have a vested interest to present an overly positive picture of the organization. A job seeker is more likely to listen and believe a person who is perceived to be knowledgeable about the subject at hand. This implies that job seekers perceive job incumbents to have higher credibility than corporate recruiters as they have on the job experience.

With respect to media credibility Cable and Yu (2006) focused on three prominent recruitment media namely electronic bulletin boards, company web pages and career fairs. The authors had predicted that job seekers would perceive electronic bulletin boards as more credible than company web site or career fairs as information available on electronic bulletin boards is generally not organization's self presentation to attract job candidates. This information is posted by a third party and is not sanitized and therefore may be perceived as more credible by the job seekers. Both websites and career fairs however are created by organizations explicitly to market themselves to the audience and thus they only try to convey positive information. However, contrary to the prediction the results suggest that company web pages and career fairs were found to be more credible than electronic bulletin boards. The reason provided is that the electronic bulletin boards are not as popular as web pages and career fairs and lack of familiarity with a medium may affect perceived credibility.

Research on effects of information from company independent sources or external sources is scarce. Most of the studies have focused on effect of the one recruitment source at a time; however in the real job market job seekers gather information from more than one source.

\section{Person environment fit}

Management Scholars have a sustained interest in the fit between employees and their work environment. P-E fit is broadly defined as the compatibility between individual and work environment that occurs when their characteristics are well matched. In the recruitment context $\mathrm{P}$-E fit perspective states that potential applicants are more attracted to environments with characteristics that are compatible to the individual characteristics (Kristof 1996; Lauver, Kristof 2001).

Lauver and Kristof (2001) distinguished between P-O fit and P-J fit. P-J fit is defined as the match between the abilities of a person and the demands of a job or the needs/desires of a person and what is provided by the job. In contrast, $\mathrm{P}-\mathrm{O}$ fit is "compatibility between people and organization that occurs when at least one entity provides what the other needs, they share similar fundamental characteristics or both" (Kristof 1996). P-J fit is specific to congruence with the job; P-O fit refers to congruence with organizational values, goals and mission.

Kristof (1996) made a distinction between "objective" and "subjective" fit. According to Kristof (1996) objective fit refers to actual fit, or fit that is defined as an empirical relationship between separate assessments of individual and organizational values. On the other hand subjective fit refers to perceived fit of how well the individual feels they would fit with the organization. Thus subjective fit represents job seeker's holistic interpretations of how well their personal characteristics match organizational characteristics. Using this conceptualization, a good fit is said to exist as long as it is perceived to exist, regardless of whether or not the person has similar characteristics to compliment or is complimented by the organization (Kristof 1996).

Cable and Judge (1996) examined the determinants of fit perceptions of new employees and job seekers and also how 
important are these fit perceptions in making job choice decisions. The authors found that of the two fit components namely objective fit and subjective fit the latter is a better predictor of individual outcomes. They operationalized fit perceptions through interviews with recruiters. It was found that job seekers subjective fit perceptions are acquired from congruence between their perceptions of organizations and their own values. Job seekers subjective fit perceptions significantly predict job choice intentions.

According to Rynes and Barber (1990) applicants can be wooed not only through improved job attributes but also through better planned and more attentive recruitment procedures. Initial contacts with on site company representatives were found to be responsible for forming initial impressions of good fit. Other than on site representatives, friends or acquaintances working with the organization were also found to influence initial good fit perceptions. Current employees can provide a better picture of job and organizational attributes; such information helps the job applicants in self-selection whether or not they fit with the job and the organization. The present study tries to investigate if information presented by current employees on company independent sites lead to better subjective fit perceptions and affect of such subjective fit perceptions on organizational attractiveness.

\section{Realistic information}

Breaugh (2008) stated that during early phase of recruitment job applicants have a) incomplete information about what job opening involves, $b$ ) are not sure of what they want from the position, c) do not have a self insight about their knowledge, skills and abilities, d) cannot accurately predict how they will react to demands of the job. Realistic information refers to presentation of positive and negative, favorable and unfavorable information about the job attributes to the job seekers (Breaugh, Starke 2000). Realistic job previews (RJP) are believed to facilitate self selection where applicants have the opportunity to analyze whether there is a fit with the job and the organization, whether there is a match between their needs, skills and what the organization is offering.

The basic premise upon which RJP is based is that job applicants most of the times do not have accurate perceptions about job they are applying. Given that employers try to be seen as good place to work for, the applicants usually have an inflated view of the organization and job. When applicants who have an inflated view are selected they are likely to be more dissatisfied and more likely to quit than who have more accurate perceptions (Breaugh, Starke 2000). As a way to reduce inflated expectations of job applicants about organization and job, organizations should try to provide both positive and negative aspects about the job. Providing RJPs will help the job applicants to have an insight about the person-job and person-organization fit.
Organizations are reluctant in providing any negative information about the job or the company. The realistic information hypothesis proposes that persons recruited via different sources are likely to have more accurate information about what the job entails (Rynes et al. 1991). Possessing such information enables a candidate to decide whether to proceed with the job and make an informed decision. Current employees would provide a better picture of how it is to work with the organization. Inclusion of both positive and negative aspects of the job may enhance trustworthiness of the company. By including some realistic information in the recruitment message, especially information that is negative yet common to many jobs (required to meet deadlines) will increase the organizational attractiveness; such recruitment message may be more persuasive than a traditional recruitment message, which gives overly positive information.

Thorsteinson et al. (2004) found that providing realistic information, on certain aspects like job and company, increases organizational attractiveness. By providing a RJP, those individuals who do not perceive a good Person Organization or Person - Job fit are able to withdraw themselves and those who remain in the applicant pool are generally the most suitable ones and should result in outcomes like employee satisfaction, retention (Breaugh, Starke 2000).

The focus of realistic job previews has largely been on post hire outcomes like job performance, satisfaction and turnover. A question that has largely been ignored is the role of RJP in the recruitment process (Thorsteinson et al. 2004). Breaugh and Starke (2000) in their article strongly urge the desire to focus heavily on job applicants than the new hires. They are of the opinion that researchers need to focus upon important pre hire variables on which recruitment sources are likely to have a more immediate impact.

\section{Propositions}

Inclusion of RJPs may increase organizational attractiveness as company is willing to provide both positive and negative information. Providing some realistic information may enhance the perceived trustworthiness of the organization. Literature on RJPs suggest that more realistic information of the job and organizational attributes help in making accurate perceptions regarding the level of congruence between abilities of the individuals and job and organizational requirements (Wanous et al. 1992; Breaugh, Starke 2000). Moreover applicants who perceive a better fit between their knowledge, skills and abilities and job and organizational requirements are likely to remain in the selection process and accept job offers.

Credibility is critically important in persuasive communication and attitude change (Perloff 1993) and is also an important variable in recruitment process (Breaugh, 
Starke 2000). Potential applicants view some information sources as more credible than others (Cable, Turban 2001) and more credible messages are more effective in generating positive attitudes towards the organization. In the recruitment context when organization may be trying to sell the organization to potential applicants more credible content is important. Using source credibility framework, compared to company dependent sources, company independent sources might be perceived as providing more credible information because they do not have explicit purpose of selling the organization (Van Hoye, Lievens 2007). Compared to company websites, information available on social media sites is less controlled by the organization. We expect that employee testimonials displayed on social media site would be perceived to be more credible than employee testimonial available on company website as the latter is a company dependent source.

Figure 1 provides a conceptual framework of the propositions made. The present study predicts that job seekers will perceive company independent sites / online communities as more credible than company websites as the information is posted by the actual employees of the company who posses more knowledge and expertise about the job and the company. Most importantly the information available on independent sites are not self presentation created by the company with the purpose to attract employees rather such sites are operated and managed by third parties and the information is not sanitized therefore it is predicted that such independent sites will be more credible.

Proposition 1: Recruitment communication or employees reviews presented on Company independent websites provide more realistic information i.e. both positive and negative information about job and organizational attributes than company websites.

Proposition 2: Recruitment communication or employees reviews presented on Company independent websites provide better Subjective P-O and P-J fit than company websites.

Proposition 3: Recruitment communication or employees reviews presented on Company independent websites will be perceived more credible than company websites.

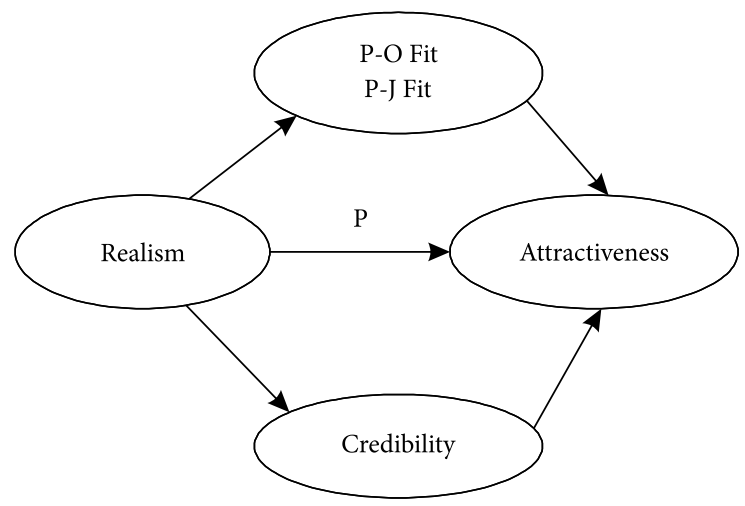

Fig. 1. Proposed framework
Proposition 4: Perceptions of organizational attractiveness will be higher when recruitment message contain realistic (positive and negative information) than when recruitment message only contains positive information.

Proposition 5: Relationship between realistic information and organizational attractiveness will be mediated by subjective P-O Fit, P-J Fit.

Propositions 6: Relationship between realistic information and organizational attractiveness will be mediated by perceived credibility.

The following propositions can be tested with reference to online reviews sites (www.glassdoor.com), where the current employees testify how it is to work with the organizations. Online reviews sites are completely third party sites therefore less expected to provide only positive information about job and organizational attributes. Online review sites can be compared with company's own webpages where the information is expected to be sanitized as it is directly under the control of the organization. The other social media tools which are used for information sharing is Facebook. Most of the organizations on Facebook have their career pages and also has anonymous confession pages for organizations. The information available on such pages have the potential of influencing the decisions to apply in the organization, LinkedIn too other than providing increased networks also provide lot of information about the job and the organization along with employee testimonials. These new media tools can be compared to know which one provides best return in terms of more realistic information, more credible information.

\section{Conclusions}

The extant literature on recruitment sources has so far majorly focused on post hire outcomes like job performance, satisfaction, turnover and intention to leave. The effect of recruitment activities on job choice decisions is still scarce and inconclusive. The recruitment has majorly focused on source credibility, the role and importance of media credibility has largely been ignored. It is evident from the literature that job incumbents as recruitment sources are perceived to be most credible as they are the ones closely associated with work and have information about job and organizational attributes (Rynes et al. 1991). Corporate recruiters are perceived to be less credible as they have an explicit intention of presenting an overly positive image of the organization before the potential applicants. As far as media credibility is concerned on one hand we have company websites as one of the prominent sources of generating pool of applicants, however the information found on company web pages is positive, as the objective is to promote the organization. On the other hand it is observed that current employees are sharing their experiences about their current or ex-employers on various forums like (www.glassdoor.com, www.vault.com) which are operated 
and managed by third parties and information available on such sites is provided by the current employees and is not sanitized before it is made available to job seekers.

In the present conceptual study we predict that employee reviews available on company independent sites will provide more realistic information that is both positive and negative features associated with the job and organization, as they are most closely associated with the job. Moreover information provided by current employees is predicted to be more credible in terms of expertise and trustworthiness. Realistic information from a credible source gives the job applicant the provisions of self-selecting himself/herself out in case the demands of the job and organization doesn't meet the requirements of the job applicant. We may infer that providing realistic information facilitates perceived fit perceptions between candidate and job and candidate and organization (P-O and P-J Fit). Therefore the present study tries to address these questions by giving a conceptual framework of whether or not company independent sites provide more realistic information, whether they provide better $\mathrm{P}-\mathrm{O}$ and P-J fit perceptions and credibility. And also how each of these variables affects organizational attractiveness.

\section{Implications and future research}

The present study tries to fill gaps in recruitment literature in few ways:

1) Job seekers initial perceptions about the organizations are very important as it would decide if the job seekers will keep the organization in the consideration set. This research would contribute to the recruitment literature by providing knowledge about using word of mouth as a source of providing recruitment related information.

2) Despite of the enormous impact of internet on recruitment practices, there is lack of research on web based sources of employment information. The research that has investigated the influence of Internet on word of mouth of recruitment has mainly investigated the role of recruitment websites, which is completely company dependent (Cable, Turban 2001).

3) The present framework will add to literature by examining the impact of social media or social networking websites on employer attractiveness. It will examine the impact of employee testimonials provided on corporate websites (company dependent sources) and social media tools (company independent). Recruitment research has majorly focused on post hire outcomes like job performance, turnover etc., however how recruitment activities influence pre hire outcomes like attractiveness towards the organization has largely been ignored.

4) This paper presents a conceptual framework on how company independent sites can influence organizational attractiveness by providing more realistic information, better-fit perceptions and increased perceived credibility. One of the managerial implications of this would be it would help to increase organizational awareness about the use and importance of word of mouth or employee testimonials as a way of providing recruitment related information. Often organizations have limited funds with respect to recruitment related activities; this study would help the organizations to channelize the funds in sources, which are perceived to be most credible and perceived to provide more realistic information to the job seeker. Job seeker's assessment of the organizational image begins at an early stage much before they actually come in direct contact with the organizations. Providing word of mouth information or employee testimonials on company independent sources can improve and modify the image perceptions about the organization. Future research can test these propositions and check if the predictions are confirmed. Future research can also test the impact of various company independent sources like chat-rooms, blogs and their relative importance in organizational attractiveness. The research on complementary effect of both traditional recruitment and recruitment through social media is one area which is scarce and is at its infancy.

\section{References}

Allen, D. G.; Scotter, J. R.; Otondo, R. F. 2004. Recruitment communication media: impact on prehire outcomes, Personnel Psychology 57(1): 143-171.

http://dx.doi.org/10.1111/j.1744-6570.2004.tb02487.x

Allen, D. G.; Biggane, J. E.; Pitts, M.; Otondo, R.; Van Scotter, J. 2013. Reactions to recruitment web sites: visual and verbal attention, attraction, and intentions to pursue employment, Journal of Business and Psychology 28(3): 263-285. http://dx.doi.org/10.1007/s10869-012-9281-6

Barber, A. E. 1998. Recruiting employees: individual and organizational perspectives. Sage Publications, Inc.

Bondarouk, T.; Ruël, H.; Weekhout, W. 2012. Employer branding and its effect on organizational attractiveness via the World Wide Web: results of quantitative and qualitative studies combined, in 4th International e-HRM Conference on Innovation, Creativity and e-HRM, 28-29 March 2012, Nottingham Trent University, UK.

Breaugh, J. A.; Starke, M. 2000. Research on employee recruitment: so many studies, so many remaining questions, Journal of Management 26(3): 405-434. http://dx.doi.org/10.1177/014920630002600303

Breaugh, J. A. 2008. Employee recruitment: current knowledge and important areas for future research, Human Resource Management Review 18(3): 103-118. http://dx.doi.org/10.1016/j.hrmr.2008.07.003

Briones, R. L.; Kuch, B.; Liu, B. F.; Jin, Y. 2011. Keeping up with the digital age: how the American Red Cross uses social media to build relationships, Public Relations Review 37(1): 37-43. http://dx.doi.org/10.1016/j.pubrev.2010.12.006 
Cable, D. M.; Judge, T. A. 1996. Person-organization fit, job choice decisions, and organizational entry, Organizational Behavior and Human Decision Processes 67(3): 294-311. http://dx.doi.org/10.1006/obhd.1996.0081

Cable, D. M.; Turban, D. B. 2001. Establishing the dimensions, sources and value of job seekers' employer knowledge during recruitment, Research in Personnel and Human Resources Management 20: 115-163. http://dx.doi.org/10.1016/S0742-7301(01)20002-4

Cable, D. M.; Yu, K. Y. T. 2006. Managing job seekers' organizational image beliefs: the role of media richness and media credibility, Journal of Applied Psychology 91(4): 828-840. http://dx.doi.org/10.1037/0021-9010.91.4.828

Cappelli, P. 2001. On-line recruiting, Harvard Business Review 79(3): 139-146.

Clark, L. A.; Roberts, S. J. 2010. Employer's use of social networking sites: a socially irresponsible practice, Journal of Business Ethics 95(4): 507-525. http://dx.doi.org/10.1007/s10551-010-0436-y

Cober, R. T.; Brown, D. J.; Keeping, L. M.; Levy, P. E. 2004. Recruitment on the net: how do organizational Web site characteristics influence, Journal of Management 30(5): 623-646. http://dx.doi.org/10.1016/j.jm.2004.03.001

Dellarocas, C. 2003. The digitization of word of mouth: promise and challenges of online feedback mechanisms, Management science 49(10): 1407-1424.

http://dx.doi.org/10.1287/mnsc.49.10.1407.17308

Dineen, B. R.; Ash, S. R.; Noe, R. A. 2002. A web of applicant attraction: person-organization fit in the context of Webbased recruitment, Journal of Applied Psychology 87(4): 723. http://dx.doi.org/10.1037/0021-9010.87.4.723

Fisher, C. D.; Ilgen, D. R.; Hoyer, W. D. 1979. Source credibility, information favorability, and job offer acceptance, Academy of Management Journal 22(1): 94-103.

http://dx.doi.org/10.2307/255481

Girard, A.; Fallery, B.; Rodhain, F. 2013. Integration of social media in recruitment: a delphi study, Advanced Series in Management 12: 97-120. http://dx.doi.org/10.1108/S1877-6361(2013)0000012009

Kaplan, A. M.; Haenlein, M. 2010. Users of the world, unite! The challenges and opportunities of Social Media, Business horizons 53(1): 59-68. http://dx.doi.org/10.1016/j.bushor.2009.09.003

Kristof, A. L. 1996. Person-organization fit: an integrative review of its conceptualizations, measurement, and implications, Personnel psychology 49(1): 1-49. http://dx.doi.org/10.1111/j.1744-6570.1996.tb01790.x

Lauver, K. J.; Kristof-Brown, A. 2001. Distinguishing between employees' perceptions of person-job and person-organization fit, Journal of Vocational Behavior 59(3): 454-470. http://dx.doi.org/10.1006/jvbe.2001.1807
Park, N.; Kee, K. F.; Valenzuela, S. 2009. Being immersed in social networking environment: Facebook groups, uses and gratifications, and social outcomes, CyberPsychology \& Behavior 12(6); 729-733. http://dx.doi.org/10.1089/cpb.2009.0003

Perloff, R. M. 1993. Third-person effect research 1983-1992: a review and synthesis, International Journal of Public Opinion Research 5(2): 167-184. http://dx.doi.org/10.1093/ijpor/5.2.167

Pornpitakpan, C. 2004. The persuasiveness of source credibility: a critical review of five decades' evidence, Journal of Applied Social Psychology 34(2): 243-281. http://dx.doi.org/10.1111/j.1559-1816.2004.tb02547.x

Rynes, S. L.; Barber, A. E. 1990. Applicant attraction strategies: an organizational perspective, Academy of Management Review 15(2): 286-310.

Rynes, S. L.; Bretz, R. D.; Gerhart, B. 1991. The importance of recruitment in job choice: a different way of looking, Personnel Psychology 44(3): 487-521. http://dx.doi.org/10.1111/j.1744-6570.1991.tb02402.x

Thorsteinson, T. J.; Palmer, E. M.; Wulff, C.; Anderson, A. 2004. Too good to be true? Using realism to enhance applicant attraction, Journal of Business and Psychology 19(1): 125-137. http://dx.doi.org/10.1023/B:JOBU.0000040276.75748.b9

Van Hoye, G.; Lievens, F. 2007. Investigating Web-based recruitment sources: employee testimonials vs word-of-mouse, International Journal of Selection and Assessment 15(4): 372-382. http://dx.doi.org/10.1111/j.1468-2389.2007.00396.x

Vicknair, J., et al. 2010. The use of social networking websites as a recruiting tool for employers, American Journal of Business Education (AJBE) 3(11): 7.

Walker, H. J., et al. 2009. Displaying employee testimonials on recruitment web sites: effects of communication media, employee race, and job seeker race on organizational attraction and information credibility, Journal of Applied Psychology 94(5): 1354-1364. http://dx.doi.org/10.1037/a0014964

Waring, R. L.; Buchanan, F. R. 2010. Social networking Web sites: the legal and ethical aspects of pre-employment screening and employee surveillance, Journal of Human Resources Education 4(2): 14-23.

Wanous, J. P., et al. 1992. The effects of met expectations on newcomer attitudes and behaviors: a review and metaanalysis, Journal of Applied Psychology 77(3): 288-297. http://dx.doi.org/10.1037/0021-9010.77.3.288

Williamson, I. O.; Lepak, D. P.; King, J. 2003. The effect of company recruitment web site orientation on individuals' perceptions of organizational attractiveness, Journal of Vocational Behavior 63(2): 242-263. http://dx.doi.org/10.1016/S0001-8791(03)00043-5

Tavleen KAUR. Research Scholar of Dept. of Human Resource Management, Faculty of Management, IFHE University, Hyderabad. Research Interests: Web based recruitment, Employer Branding.

Ritesh Kumar DUBEY. Research Scholar of Dept. of Finance, Faculty of Management, IFHE University, Hyderabad. Research Interests: Behavioral Finance, Corporate Finance. 